\title{
Potencial envolvimento da adiponectina e seus receptores na modulação da esteroidogênese em corpo lúteo de cadelas ao longo do diestro ${ }^{1}$
}

\author{
Vanessa U. Fonseca ${ }^{2 *}$, Paula C. Papa ${ }^{2}$ e Danila B. Campos ${ }^{3}$
}

\begin{abstract}
Fonseca V.U., Papa P.C. \& Campos D.B. 2012. [Potential involvement of adinopectin and its receptors in the modulation of steroidogenesis in corpus luteum of bitches during diestrus.] Potencial envolvimento da adiponectina e seus receptores na modulação da esteroidogênese em corpo lúteo de cadelas ao longo do diestro. Pesquisa Veterinária Brasileira 32(10):1055-1060. Setor de Anatomia, Departamento de Cirurgia, Faculdade de Medicina Veterinária e Zootecnia, Universidade de São Paulo, Av. Prof. Dr. Orlando Marques Paiva 87, SP 05508-270, Brazil. E-mail: uemura@usp.br

In the estrous cycle of bitches, the luteal phase or diestrus includes a period ranging from 60 to 100 days in non-pregnant animals, characterized by elevated serum progesterone during the first 20 days post-ovulation (p.o). Adiponectin is the most abundant protein secreted by adipose tissue, but plasma concentration decreases significantly in metabolic disorders like insulin resistance and diabetes mellitus type 2, described as related changes in some bitches in diestrus. The aim of this study was to determine the expression and immunolocalization of the adiponectin system (adiponectin, and adipoR1 adipoR2) in the corpus luteum during diestrus, and correlate it to hormonal profile of $17 \beta$-estradiol and progesterone, as well as the expression of a gene target of the system, the PPAR- $\gamma$. For the study, corpora lutea were collected from 28 dogs during ovariosalpingohysterectomy on days $10,20,30,40,50,60$ and 70 post ovulation (day zero of ovulation was considered the day when the plasma progesterone concentration reached $5 \mathrm{ng} / \mathrm{mL}$ ). The corpora lutea were evaluated by immunohistochemistry for adiponectin, adipoR1 and adipoR2 and mRNA expression of PPAR- $\gamma$ by real-time PCR. Statistical analysis of gene expression was performed with ANOVA followed by Newman-Keuls multiple comparisons. Adiponectin positive signal was stronger during the first 20 days p.o, time of the regency of progesterone; there was a gradual adiponectin and progesterone decline after this period, coinciding with the rise of $17 \beta$-estradiol, whose peak was near the 40 days p.o. The markedly adiponectin decrease occurred after 50 days p.o. The signal of adipoR1 was markedly evident at 40 days p.o and that of adipoR2 up to 50 days p.o, declining afterwards. We observed higher expression of PPAR- $\gamma$ gene at 10, 30 and 70 days p.o. These results show that adiponectin and its receptors protein expression is altered during the diestrus and that these changes may be related to hormonal changes and expression of PPAR- $\gamma$, participating in the physiological mechanism of development, maintenance, activity and luteal regression in bitches.
\end{abstract}

INDEX TERMS: Corpus luteum, adiponectin, adipoR1, adipoR2 and PPAR- $\gamma$.

\footnotetext{
${ }^{1}$ Recebido em 15 de marco de 2012.

Aceito para publicação em 28 de junho de 2012.

${ }^{2}$ Setor de Anatomia, Departamento de Cirurgia, Faculdade de Medicina Veterinária e Zootecnia (FMVZ), Universidade de São Paulo (USP), Av. Prof. Dr. Orlando Marques Paiva 87, São Paulo, SP 05508-270, Brasil. *Autor para correspondência: uemura@usp.br

${ }^{3}$ Centro de Ciências Agrárias, Universidade Federal da Paraíba, Areia, PB 58397-000, Brasil. E-mail: camposdb@usp.br
}

RESUMO.- No ciclo estral de cadelas a fase luteínica, denominada diestro, compreende um período que varia de 60 a 100 dias em animais não-prenhes, caracterizado pela elevação plasmática de progesterona nos primeiros 20 dias pós ovulação (p.o). A adiponectina é a mais abundante proteína secretada pelo tecido adiposo, porém sua concentração plasmática diminui significativamente em alterações metabólicas como resistência insulínica e Diabetes mellitus 
tipo 2, alterações descritas como relacionadas em algumas cadelas com o período de diestro. 0 objetivo do estudo foi determinar a expressão e imunolocalização do sistema adiponectina (adiponectina e seus receptores, adipoR1 e adipoR2) no corpo lúteo de cadelas ao longo do diestro, correlacionando-o ao perfil hormonal de $17 \beta$-estradiol e progesterona, assim como à expressão de um dos genes alvo do sistema, o PPAR- $\gamma$. Para realização do estudo foram coletados corpos lúteos de 28 cadelas durante ovariosalpingohisterectomia de eleição nos dias 10, 20, 30, 40, 50, 60 e 70 pós ovulação (o dia zero da ovulação foi considerado aquele no qual a concentração plasmática de progesterona atingiu $5 \mathrm{ng} / \mathrm{mL}$ ). Os corpos lúteos foram avaliados por imunohistoquímica para adiponectina e seus receptores e a expressão do RNAm do PPAR- $\gamma$ por PCR em tempo real. A análise estatística da avaliação gênica foi realizada com o teste ANOVA, seguido por comparação múltipla Newman-Keuls . O sinal da adiponectina apresentou-se mais intenso até os primeiros 20 dias p.o, momento de regência da progesterona; houve queda gradativa após este período, coincidindo com a ascensão do $17 \beta$-estradiol, cujo pico foi notado próximo do dia 40 p.o. A queda marcante da adiponectina ocorreu após 50 dias p.o. 0 sinal do adipoR1 mostrou-se bem evidente até os 40 dias p.o e o do adipoR2 até os 50 dias p. o, decaindo posteriormente. Foi observada maior expressão do gene PPAR- $\gamma$ aos 10, 30 e 70 dias p.o. Estes resultados mostram que a expressão protéica da adiponectina e de seus receptores se altera ao longo do diestro e que estas alterações podem estar relacionados às alterações hormonais e expressão do PPAR- $\gamma$, participando do mecanismo fisiológico de desenvolvimento, manutenção, atividade e regressão luteínica em cadelas.

TERMOS DE INDEXAÇÃO: Corpo lúteo, diestro, adiponectina, adipoR1, adipoR2 e PPAR- $\gamma$.

\section{INTRODUÇÃO}

O cão doméstico (Canis familiaris) é uma espécie monoéstrica não sazonal, de ovulação espontânea, cuja atividade reprodutiva compreende um período de pró-estro (13-16 dias), estro (4-12 dias) e diestro (60-100 dias), seguido de um período de anestro que varia de 15 a 165 dias (Stabenfeldt \& Shille 1977). A produção de progesterona ( $\mathrm{P}_{4}$ ) de origem folicular se inicia no final do pró-estro antes da ovulação, atingindo níveis plasmáticos periféricos de aproximadamente $5 \mathrm{ng} / \mathrm{mL}$ no momento da ovulação (Concannon et al. 1989). A formação do corpo lúteo (CL) é indicada por um aumento contínuo dos níveis de progesterona periférica, que em geral atingem valores máximos durante os primeiros 20 dias de diestro. Este período é seguido por um declínio contínuo de progesterona para níveis de $<1 \mathrm{ng} / \mathrm{ml}$ (Concannon et al. 1993). Neste contexto, o corpo lúteo é uma glândula endócrina temporária, que passa por um processo de desenvolvimento, manutenção e regressão, atingindo atividade secretória plena quando sua formação está completa (Stouffer et al. 2006).

A adiponectina é a mais abundante proteína secretada pelo tecido adiposo (também conhecida como Acrp30, AdipoQ, GBP28 e AMP1) (Berg et al. 2002), porém sua con- centração plasmática diminui significativamente em alterações metabólicas como obesidade e Diabetes mellitus tipo 2 , sugerindo que a adiponectina circulante esteja relacionada com o estabelecimento da resistência insulínica (Weyer et al. 2001, Yaturu et al. 2006, Kadowaki \& Yamauchi 2005, Ishioka et al. 2006), alterações descritas como relacionadas em algumas cadelas com o período de diestro (Feldman \& Nelson 2004). Os efeitos metabólicos da adiponectina são diversos, atua como promotora do aumento da oxidação lipídica no músculo esquelético (Fruebis et al. 2001, Yamauchi et al. 2001), na redução da produção de glicose hepática (Berg et al. 2001, Combs et al. 2001) e aumento na sensibilidade insulínica (Kadowaki \& Yamauchi, 2005).

Os receptores de adiponectina 1 e 2 (AdipoR1 e AdipoR2) foram identificados em diferentes espécies, incluindo seres humanos, roedores (Yamauchi et al. 2003), suínos (Lord et al. 2005) e galinhas (Ramachandran et al. 2006). Em humanos e camundongos o AdipoR1 é expresso predominantemente no músculo esquelético e o AdipoR2 no tecido hepático (Yamauchi et al. 2003). Nos suínos, o RNAm do AdipoR1 é mais abundante nos músculos esqueléticos, tecidos adiposos subcutâneo e visceral, enquanto o RNAm do AdipoR2 foi identificado principalmente no fígado, coração, músculo esquelético e tecidos adiposos subcutâneo e visceral (Lord et al. 2004). AdipoR1 é descrito como sendo ligado principalmente à ativação de vias AMPK que regulam a inibição da gliconeogênese, juntamente com o aumento da oxidação dos ácidos graxos, enquanto o AdipoR2 está mais envolvido na ativação das vias PPAR (peroxissome proliferator activated receptor) que estimulam a dissipação de energia através do aumento da oxidação de ácidos graxos, inibe o estresse oxidativo e inflamação (Capeau 2007).

Os efeitos da adiponectina nos tecidos reprodutivos são estudados por diversos grupos de pesquisa que demonstraram, por exemplo, que a molécula pode estar envolvida negativamente na esteroidogênese em pacientes humanos com síndrome do ovário policístico (SOPC), condição marcada pela hipoadiponectinemia, hiperandrogenismo, resistência à insulina e anomalias vasculares ovarianas (Panidis et al. 2003, Ardawi \& Rouzi 2005, Campos et al. 2007). Recentemente, foram localizadas, através da imunohistoquímica, a presença de adiponectina e seus receptores adipoR1 e adipoR2 nas células da teca, corpo lúteo, oócito e com menor intensidade nas células da granulosa de ratos (Chabrolle et al. 2007). As vias metabólicas no corpo lúteo podem influenciar diretamente a produção hormonal e contribuir para o estado de resistência insulínica observado durante o diestro (Papa et al., 2011).

0 presente estudo foi delineado para determinar a expressão e imunolocalização do sistema adiponectina (adiponectina, adipoR1 e adipoR2) ao longo do diestro no CL das cadelas, correlacionando-o ao perfil hormonal de estradiol e progesterona, assim como à expressão de um dos genes alvo do sistema, o PPAR- $\gamma$.

\section{MATERIAL E MÉTODOS}

Foram utilizados corpos lúteos coletados durante campanha de castração de 28 cadelas de diferentes idades e sem padrão racial definido divididas em grupos ovariosalpingohisterectomizados 
aos $10(\mathrm{n}=3), 20(\mathrm{n}=4), 30(\mathrm{n}=4), 40(\mathrm{n}=5), 50(\mathrm{n}=4), 60(\mathrm{n}=3)$ e $70(n=5)$ dias após a ovulação. 0 projeto foi executado sob aprovação do comitê de Bioética da Faculdade de Medicina Veterinária e Zootecnia da Universidade de São Paulo (número de processo 1432/2008). 0 acompanhamento das cadelas a serem ovariohisterectomizadas ocorreu a partir do surgimento de sinais de proestro, como edema vulvar e secreção vaginal sanguinolenta. Com o surgimento de tais sinais foram iniciadas as coletas de sangue, feitas em dias alternados. A partir desse material foram realizadas dosagens de progesterona e $17 \beta$-estradiol séricos por meio do radioimunoensaio (DSL-3400, Genese, EUA) a fim de detectar a data de ovulação de cada animal e programar as cirurgias para a obtenção dos corpos lúteos ao longo do diestro.

Os tecidos coletados foram fixados em formol tamponado $4 \%$ durante 24 horas, seguido da fase de inclusão, onde os tecidos foram desidratados em concentrações crescentes de álcoois, diafanizados em xilóis e incluídos em parafina. Os cortes de aproximadamente $5 \mu \mathrm{m}$ foram obtidos em micrótomo (Leica Microsystems RM2235), sendo fixados em lâminas silanizadas. Durante o procedimento de imunolocalização as lâminas foram desparafinizadas em xilol, os cortes re-hidratados sucessivamente em uma série decrescente de alcoóis, passadas em solução citrato $10 \mathrm{mM} \mathrm{pH} \mathrm{6,0}$ à temperatura ambiente e sob fervura para exposição antigênica. A atividade da peroxidase endógena foi bloqueada com peróxido de hidrogênio a $1 \%$ em metanol e as ligações inespecíficas reduzidas após incubação em solução de soro de cabra em tampão fosfato (PBS). Em seguida, os cortes foram incubados overnight à $4^{\circ} \mathrm{C}$ com anticorpos primários na diluição 1:200 para adiponectina (ab22554, Abcam), adipoR1 e adipoR2 (H-001-44 e H-001-23, Phoenix Pharmaceuticals). Após o período de incubação com o anticorpo primário, as lâminas foram lavadas em PBS, e então incubadas à temperatura ambiente durante 1 hora, com o segundo anticorpo biotinilado anti camundongo para adiponectina e anti coelho para os receptores na diluição 1:200 (Abcam). Em seguida, o sinal foi amplificado com o complexo de peroxidase-estreptovidina-biotina, (ABC-Method; Vectastain-Universal-ELITE-ABC-Kit $\AA$, Vector Laboratories) e revelado com Nova Red® (Vector Laboratories).

O RNA total foi isolado de corpos lúteos a partir do protocolo Trizol® (Invitrogen, USA) e o DNA complementar confeccionado com a Superscript III ${ }^{\circledR}$ (Invitrogen, USA) após tratamento com DNase I, de acordo com os protocolos do fabricante. O PCR em tempo real foi realizado para quantificar a expressão do PPAR- $\gamma$ durante o diestro. 0 aparelho utilizado foi o ABIPrism® 7500 (Applied Biosystems, Foster, USA). Como controle interno das reacões foi utilizado a amplificacão do gene constitutivo ciclofilina, a fim de normalizar os resultados obtidos para os genes alvo. As sequências de primers e sondas usados para ciclofilina são de identificação ID Cf03986523 -gH (Applied Biosystems, Foster, USA), PPAR- $\gamma$ sense 5'-GGC CCT GGC AAA ACA TTT G - $3^{\prime}$, anti-sense 5'TCG CTC TCG CCT TTG CTT T $-3^{\prime}$ e sonda $5^{\prime}$-ATG ACT CAT ACA TAA AGT CCT TCC CGC - 3 '. As reações foram realizadas utilizando

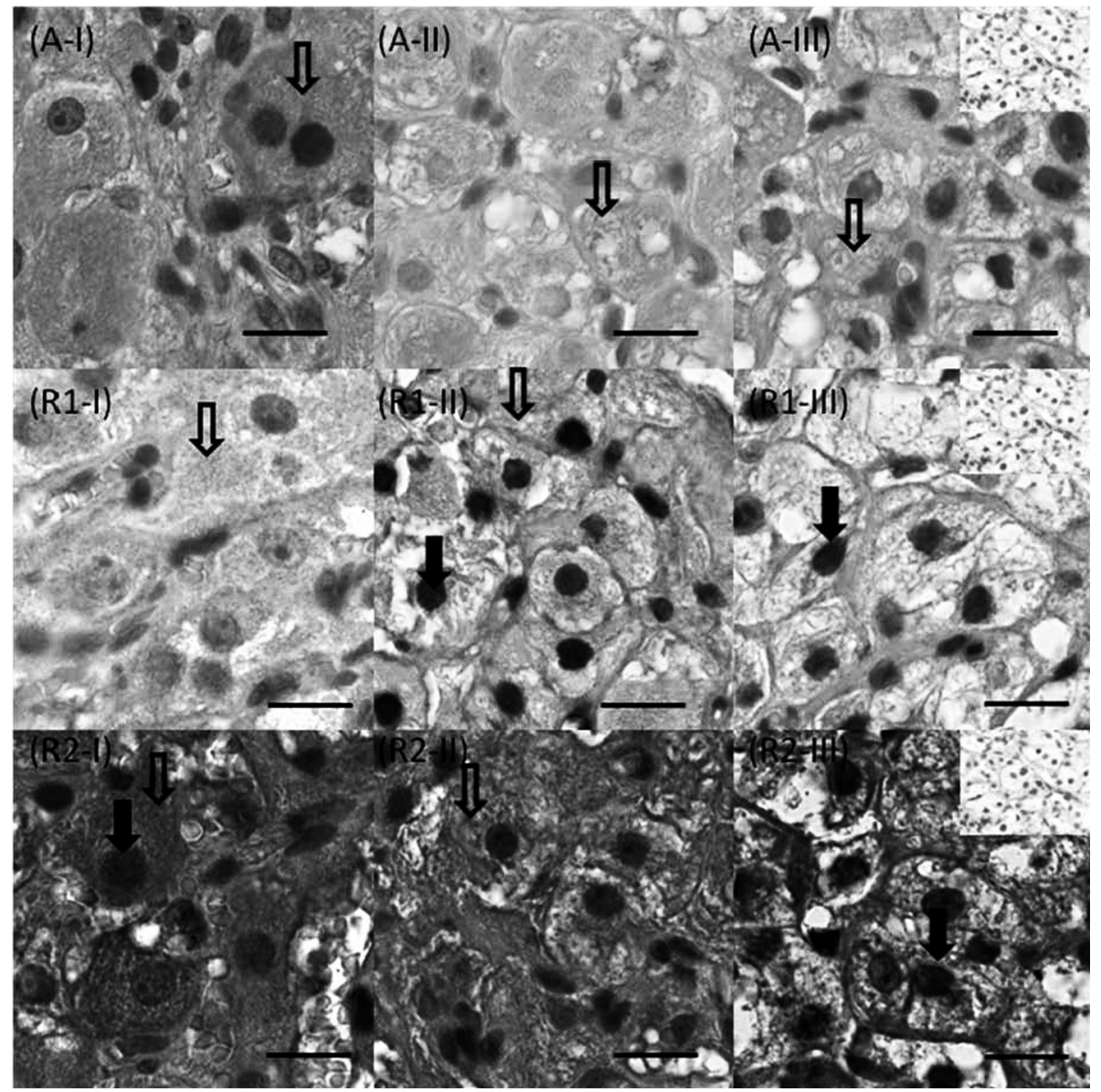

Fig.1. Adiponectina (A), AdipoR1 (R1) e AdipoR2 (R2) no corpo lúteo de cadelas com 20 (A-I, R1-I e R2-I), 40 (A-II, R1-II e R2-II) e 60 (A-III, R1-III e R2-III ) dias após a ovulação. Imagens no canto superior direito correspondem aos controles negativos sem a utilização de anticorpos primários. As setas sem preenchimento correspondem à marcação citoplasmática e as setas preenchidas à marcação nuclear. Barras $=25 \mu \mathrm{m}$. 
o sistema TaqMan® (Applied Biosystems, Foster, USA), conduzidas em duplicatas para cada amostra e a quantificação relativa de PPAR- $\gamma$ foi feita normalizando-se os sinais desses genes com o sinal da ciclofilina, através do programa LinRegPCR $®$ versão 7.0 (RAMAKERS et al. 2003), seguido do método matemático de Pfaffl (PFAFFL et al. 2001) e análise estatística dos dados. A análise estatística da avaliação gênica foi realizada com o teste ANOVA, seguido por comparação múltipla Newman-Keuls (GraphPad Software Inc., San Diego, CA, USA), sendo significativo p<0,05.

\section{RESULTADOS}

O sinal da adiponectina foi detectado no corpo lúteo, através da imunohistoquímica, ao longo do diestro. 0 sinal apresenta-se mais forte até os primeiros 20 dias pós ovulação (p.o) (Fig.1A-I). Após este período há uma queda gradativa do sinal, sendo marcadamente menor após 50 dias p.o., persistindo aos 60 e 70 dias p.o (Fig.1A-III). Este sinal foi observado somente no citoplasma das células luteínicas, e não houve expressão no compartimento nuclear em nenhum dos períodos estudados. 0 sinal do receptor adipoR1 no corpo lúteo mostra-se intenso até os 40 dias (Fig.1R1-I e II) após a ovulação; subsequentemente observa-se uma queda gradativa na expressão de adipoR1. 0 estudo de imunolocalização do receptor AdipoR1 evidencia que este se encontra predominantemente fora do compartimento nuclear até os 30 dias p.o, entretanto há marcante internalização nuclear após 40 dias p.o (Fig.1R1-II). 0 receptor adipoR2 é mais expresso no corpo lúteo até os 50 dias p. o, como representado aos 20 e 40 dias p.o (Fig.1R2-I e II), decaindo o sinal positivo posteriormente. Durante os 30 primeiros dias p.o, o receptor AdipoR2 aparece internalizado no compartimento nuclear, com significativa redução de expressão neste compartimento aos 40 e 50 p.o (Fig.1R2-II), e internalização novamente aos 60 dias p.o (Fig.1R2-III).

A adiponectina acompanha a expressão citoplasmática de seus receptores nas fases iniciais do diestro, momento de formação do corpo lúteo e ascensão nos níveis séricos de progesterona (figura 2). Foi observado que há crescente nível de $17 \beta$-estradiol sérico a partir do dia 25 p.o., momento de menor expressão da adiponectina, com pico no dia 45 p.o., coincidindo com a menor compartimentalização nuclear do adipoR2, e posterior redução dos níveis séricos de $17 \beta$-estradiol sérico.

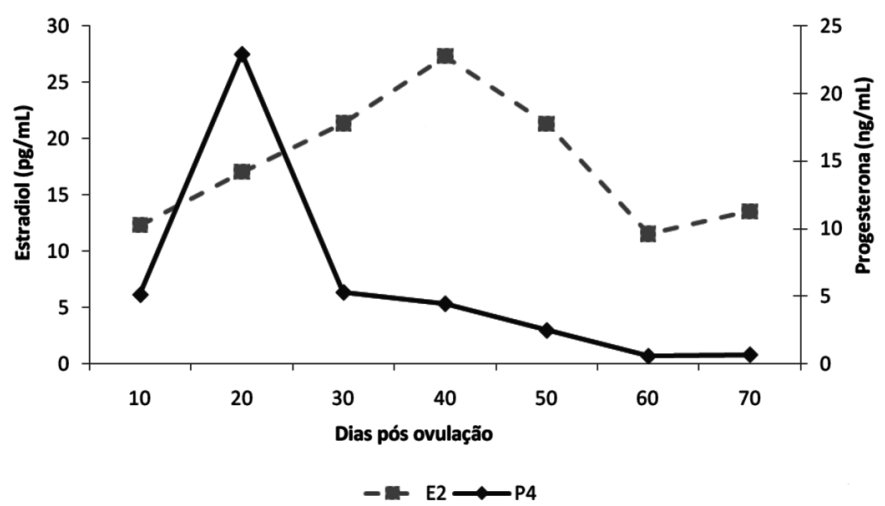

Fig.2. Análise do perfil de progesterona e estradiol durante o diestro de cadelas.

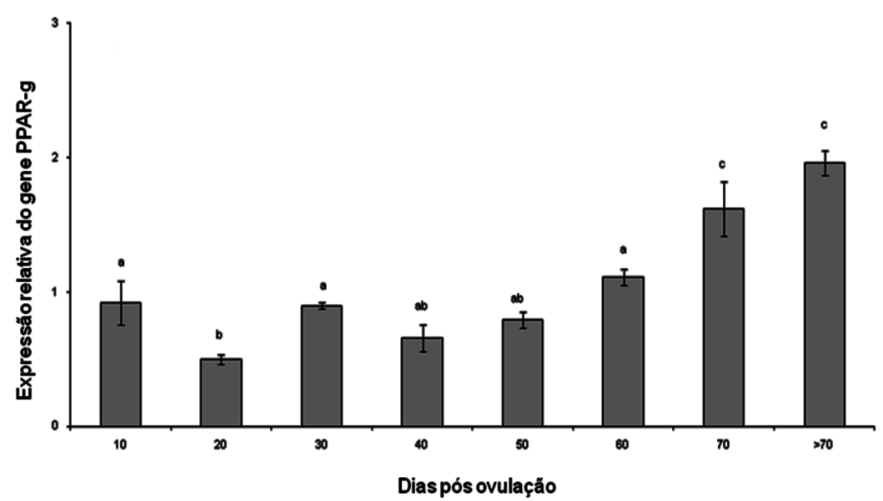

Fig.3. Quantificação da expressão do PPAR- $\gamma$ em relação ao gene controle ciclofilina (média \pm desvio padrão, $n=4$ por grupo) no corpo lúteo ao longo do diestro.

A análise da expressão relativa do RNAm de PPAR- $\gamma$ (Fig.3) revelou que houve queda significativa $(p<0,05)$ aos 20 dias p.o, momento de regência da progesterona, em relação a 30,60 e 70 dias p.o. A expressão do gene é significativamente maior $(\mathrm{p}<0,05)$ aos 60 dias p.o em relação aos 20 dias p.o. e observa-se também significativo aumento de expressão após 70 dias em relação aos demais períodos em estudo.

\section{DISCUSSÃO}

Este é o primeiro relato da presença da adiponectina e seus receptores no corpo lúteo (CL) de cadelas, detectada ao longo do período de diestro, sendo marcante o declínio do sinal aos 50 dias p.o. Efeito semelhante foi observado na expressão do VEGF (fator de crescimento vascular endotelial) e seus receptores, Flt-1 e KDR ao longo do diestro (Mariani et al. 2006). A adiponectina em células da granulosa de ovários suínos induziu maior expressão gênica resultando em síntese de prostaglandinas e do fator de crescimento vascular endotelial (VEGF) (Ledoux et al. 2006). Chabrolle e colaboradores (2007) observaram uma forte expressão da adiponectina no corpo lúteo de ratos sugerindo que esta molécula esteja envolvida no crescimento e desenvolvimento luteínico. 0 presente estudo mostrou que a adiponectina possui maior expressão citoplasmática nos primeiros 20 dias p.o, momento de formação do corpo lúteo canino corroborando com a sugestão de que a adiponectina é uma molécula importante no processo de crescimento e maturação destas células e ainda na produção de progesterona. Os dados apresentados (Fig.1) demonstram que o sistema adiponectina (adiponectina e receptores) possivelmente esteja correlacionado com o processo estereoidogênico nas células luteínicas (Fig.2). Além disso, a adiponectina acompanha a expressão citoplasmática de seus receptores nas fases iniciais do diestro, momento no qual ocorre a ascensão dos níveis séricos de progesterona, e decréscimo significativo na fase final, momento de regressão e domínio estrogênico.

A adiponectina exerce sua ação por ligar-se em dois receptores específicos, adipoR1 e adipoR2. Estes receptores são essenciais para a sinalização da adiponectina via AMPK (proteína quinase ativada por adenosina monofosfato), MAPK (proteínas-quinases ativadas por mitógenos) e PPAR 
(Yamauchi et al. 2003). A adiponectina ativa a AMPK em vários tipos celulares (Huypens et al. 2005, Yoon et al. 2006), e participa do aumento de captação de glicose (Fujii et al. 2006, Ju et al. 2007) com papel importante na maturação de oócitos de camundongos (Downs et al. 2002, Chen et al. 2006). Em células da granulosa de humanos, o adipoR1 parece estar envolvido com a sobrevivência celular, enquanto que o adipoR2, através da ativação MAPK ERK1/2, pode modular a produção esteroidogênica na presença de FSH e IGF-1 (Pierre et al. 2009). Em células da granulosa de rato a adiponectina aumenta a produção de progesterona e estradiol induzida por IGF-I, após fosforilação de MAPK (ERK1/2 e p38) e via Akt (Chabrolle et al. 2007). A imunolocalização dos receptores mostrou a presença dos receptores adipoR1 e adipoR2 internalizados no núcleo, sobre a carioteca ou em síntese em retículos endoplasmáticos rugosos adjacentes ao compartimento nuclear. A sugestão de que os receptores possam estar compartimentalizados em sítio nuclear não foi até o momento descrito, pois são descritos apenas como tendo domínios transmembrânicos (Buechler et al. 2010), sem atuação direta sobre o núcleo celular. Entretanto, este pode ser um mecanismo celular de poupar energia, visto que a compartimentalização nuclear evitaria a renovação destes receptores e destruição por via enzimática em citoplasma. A menor internalização nuclear do AdipoR1, sendo este ligado principalmente às vias AMPK (Capeau 2007), coincide com a fase de crescimento e desenvolvimento do corpo lúteo até 20 dias p.o, sendo que no momento em que o corpo lúteo está maduro e entra na fase de regressão há maior internalização nuclear deste receptor. Já o AdipoR2 comporta-se de maneira distinta quanto à compartimentalização nuclear, sendo menor sua internalização aos 40 p.o, momento de predomínio do estradiol. Neste contexto, sugere-se que o AdipoR2 esteja envolvido com a modulação esteroidogênica que ocorre nesta fase luteínica.

0 PPAR- $\gamma$ regula genes envolvidos com diferenciação de adipócitos, armazenamento e mobilização de lipídeos, metabolismo da glicose, atividade da lipoproteína lípase e expressão de adipocinas (Spiegelman, 1998). A maior expressão do gene PPAR- $\gamma$ aos 10 dias p.o (Fig.3) em relação aos 20 dias p.o, momento de pico de progesterona no diestro, coincide com o momento de ascensão da produção deste hormônio neste estudo, como ocorreu quando as células luteínicas foram tratadas in vitro com um ligante do PPAR- $\gamma$ (Keller et al. 1995). Houve maior expressão deste gene aos 30 dias p.o coincidindo com momento de crescente síntese de estradiol e menor compartimentalização do adipoR2 no núcleo, em relação ao dia 20 p.o. Estudo prévio demonstrou que o AdipoR2 está mais envolvido na ativação das vias PPAR, dentre os diversos efeitos que surgem desta interação, há maior inibição do estresse oxidativo e inflamação (Capeau 2007). Desta forma, sugere-se que o adipoR2 e o PPAR- $\gamma$ estejam correlacionados e modulem a síntese de progesterona e estradiol ao longo do diestro, e que sua atividade antioxidante auxilie na manutenção das células luteínicas neste processo de intensa atividade esteroidogênica.

No processo de regressão do CL sinais característicos de degeneração foram observados no dia 60 , quando os núcle- os se tornaram picnóticos, poligonais e apresentaram início da condensação de cromatina e grandes gotículas lipídicas em torno do retículo endoplasmático liso. Sinais de apoptose após o dia 65 foram observados também pelo método de TUNEL e caspase 3 (Sonnack et al. 2003). 0 significativo aumento na expressão do PPAR- $\gamma$ que observamos após 70 dias, pode estar relacionado com este processo de apoptose celular e regressão do CL. A maior expressão e ativação do PPAR- $\gamma$ já foi descrita como indutora de apoptose em diferentes tipos celulares (Takahashi et al. 1999, Harris \& Phipps 2001).

\section{CONCLUSÃO}

Conclui-se que a expressão protéica da adiponectina e seus receptores se altera ao longo do diestro e que estas alterações podem estar relacionados às alterações hormonais e expressão do PPAR- $\gamma$ participando do mecanismo fisiológico de desenvolvimento, manutenção, atividade e regressão luteínica em cadelas.

\section{REFERÊNCIAS}

Ardawi M.S. \& Rouzi A.A. 2005. Plasma adiponectin and insulin resistance in women with polycystic ovary syndrome. Fertil. Steril. 84:1708-1716.

Berg A.H., Combs T.P., Du X., Brownlee M. \& Scherer P.E. 2001. The adipocyte-secreted protein Acrp30 enhances hepatic insulin action. Nature Med. 7:947-953.

Berg A.H., Combs T.P. \& Scherer P.E. 2002. ACRP30/adiponectin: an adipokine regulating glucose and lipid metabolism. Trends Endocrinol. Metabol. 13:84-89.

Buechler C., Wanninger J. \& Markus N. 2010. Adiponectin receptor binding proteins- recent advances in elucidating adiponectin signalling pathways. FEBS Letters 584:4280-4286.

Campos D.B., Palin M-F., Bordignon V. \& Murphy B.D. 2007. The beneficial adipokines in reproduction and fertility. Int. J. Obesity 32:223-231.

Capeau J. 2007. The story of adiponectin and its receptors AdipoR1 and R2: To follow. J. Hepatol. 47:736-738.

Chabrolle C., Tosca L. \& Dupont J. 2007. Regulation of adiponectin and its receptors in rat ovary by human chorionic gonadotrophin treatment and potential involvement of adiponectin in granulosa cell steroidogenesis. Reproduction 133:719-731.

Chen J., Hudson E., Chi M.M., Chang A.S., Moley K.H., Hardie D.G. \& Downs S.M. 2006. AMPK regulation of mouse oocyte meiotic resumption in vitro. Dev. Biol. 291:227-238.

Combs T.P., Berg A.H., Obici S., Scherer P.E. \& Rossetti L. 2001. Endogenous glucose production is inhibited by the adipose-derived protein Acrp30. J. Clin. Invest. 108:1875-1881.

Concannon P.W., McCann J.P. \& Temple M. 1989. Biology and endocrinology of ovulation, pregnacy and parturiation in the dog. J. Reprod. Fertil. 39:3-25.

Concannon P.W. 1993. Biology of gonadotrophin secretion in adult and prepubertal female dogs. J. Reprod. Fertil. 47:3-27.

Downs S.M., Hudson E.R. \& Hardie D.G. 2002. A potential role of AMPactivated protein kinase in meiotic induction in mouse oocytes. Dev. Biol. 245:200-212.

Feldman E.C. \& Nelson R.W. 2004. Ovarion cycle and vaginal cytology, p.766-790. In: Feldman E.C. \& Nelson R.W. (Eds), Canine and Feline Endocrinology and Reproduction. $3^{\text {rd }}$ ed. W.B. Saunders, Philadelphia.

Fruebis J., Tsao T.S., Javorschi S., Ebbets-Reed D., Erickson M.R., Yen F.T., Bihain B.E. \& Lodish H.F. 2001. Proteolytic cleavage product of 30-kDa adipocyte complement-related protein increases fatty acid oxidation in muscle and causes weight loss in mice. Proc. Natl Acad. Sci. USA 98:2005-2010.

Fujii N., Jessen N. \& Goodyear L.J. 2006. AMP-activated protein kinase and 
the regulation of glucose transport. Am. J. Physiol. Endocrinol. Metabol. 291:867-877.

Kadowaki T. \& Yamauchi T. 2005. Adiponectin and adiponectin receptors. Endocrine Rev. 26:439-451.

Harris S.G. \& Phipps R.P. 2001. The nuclear receptor PPAR gamma is expressed by mouse $\mathrm{T}$ lymphocytes and PPAR gamma agonists induce apoptosis. Eur. J. Immunol. 31:1098-1105.

Huypens P., Moens K., Heimberg H., Ling Z., Pipeleers D. \& Van de Casteele M. 2005. Adiponectin-mediated stimulation of AMPactivated protein kinase (AMPK) in pancreatic beta cells. Life Sci 77:1273-1282.

Ju J.S., Gitcho M.A., Casmaer C.A., Patil P.B., Han D.G., Spencer S.A. \& Fisher J.S. 2007. Potentiation of insulin-stimulated glucose transport by the AMP-activated protein kinase. Am. J. Physiol. Cell. Physiol. 292:564-572.

Ledoux S., Campos D.B., Lopes F.L., Dobias-Goff M., Palin M.F. \& Murphy B.D. 2006. Adiponectin induces periovulatory changes in ovarian follicular cells. Endocrinology 147:5178-5186.

Lord E., Ledoux S., Murphy B.D., Beaudry D. \& Palin M.F. 2005. Expression of adiponectin and its receptors in swine. J. Anim. Sci. 83:565-578.

Ishioka K., Omachi A., Sagawa M., Shibata H., Honjoh T., Kimura K. \& Saito M. 2006. Canine adiponectin: cDNA structure, mRNA expression in adipose tissues and reduced plasma levels in obesity. Res. Vet. Sci. 80:127132.

Keller H., Wahli W. \& Perroud M. 1995. Signaling cross-talk between peroxisome proliferator-activated receptor/retinoid X receptor and estrogen receptor through estrogen response elements. Mol. Endocrinol. 9:794-804.

Mariani T.C., Prado C., Silva L.G., Paarmann F.A., Lima M.C., Carvalho I., Campos D.B., Artoni L.P., Hernandez-Blazquez F.J. \& Papa P.C. 2006. Immunohistochemical localization of VEGF and its receptors in the corpus luteum of the bitch during diestrus and anestrus. Theriogenology 66:1715-1750.

Panidis D., Kourtis A., Farmakiotis D., Mouslech T., Rousso D. \& Koliakos G. 2003. Serum adiponectin levels in women with polycystic ovary syndrome. Human Reprod. 18:1790-1796.

Papa P.C., Kowalewski M., Sousa L.M., Fátima L., Fonseca V.U., Silva R.S., Dias C. \& Boos A. 2011. Corpus luteum and diestrus in the bitch: A study model for hormonal-dependent metabolic alterations. Anais 44을 Congresso da Sociedade para Estudos em Reprodução (SSR), Portland, Resumo 225. (http://www.ssr.org/Documents/2011-07-25Abstracts201-300. pdf)

Pfaffl M.W. 2001. A new mathematical model for relative quantification real time RT-PCR. Nucleic Acids Res. 29:2002-2007.

Pierre P, Froment P., Négre D., Ramé C., Barateau V., Chabrolle C., Lecomte
P. \& Dupont J. 2009. Role of adiponectin receptors, AdipoR1 and AdipoR2, in the steroidogenesis of the human granulosa tumor cell line, KGN. Human Reprod. 24:2890-2901.

Ramachandran R., Ocon-Grove O.M. \& Metzger S.L. 2006. Molecular cloning and tissue expression of chicken AdipoR1 and AdipoR2 complementary deoxyribonucleic acids. Domestic Anim. Endocrinol. 33:19-31.

Ramakers J., Ruijter J.M., Deprez R.L.H. \& Moorman A.F.M. 2003. Assumption-free analysis of quantitative real-time polymerase chain reaction (PCR) data. Neurosci. Letters 339:62-66.

Sonnack M., Leiser R., Meyer W. \& Hoffmann B. 2003. Morphological changes in the regressing canine corpus luteum and the occurrence of apoptotic events. Reproduc in Domestic Anim. 38:354-355.

Stabenfeldt G.H. \& Shille V.M. 1977. Reproduction in the dog and cat, p.499-527. In: Cole H.H. \& Cupps P.T. (Eds), Reproduction in Domestic Animals. Academic Press, NewYork.

Stouffer R.L. 2006. Structure, function and regulation of the corpus luteum, p.475-526. In: Neill J.D. (Ed.), Physiology of Reproduction. Elsevier, Amsterdam.

Takahashi N., Okumura T., Motomura W., Fujimoto Y., Kawabata I. \& Kohgo Y. 1999. FEBS Letters 455:135-139.

Weyer C., Funahashi T., Tanaka S., Hotta K., Matsuzawa Y., Pratley R.E. \& Tataranni A. 2001. Hypoadiponectinemia in Obesity and Type 2 Diabetes: close association with insulin resistance and Hyperinsulinemia. J. Clin. Endoc. Metab. 86:1930-1935.

Yamauchi T., Kamon J., Waki H., Terauchi Y., Kubota N., Hara K., Mori Y., Ide T., Murakami K., Tsuboyama-Kasaoka N., Ezaki E., Akanuma Y., Gavrilova O., Vinson C., Reitman M.L., Kagechika H., Shudo K., Yoda, M., Nakano Y., Tobe K., Nagai R., Tomita M., Froguel P. \& Kadowaki T. 2001. The fatderived hormone adiponectin reverses insulin resistance associated with both lipoatrophy and obesity. Nature Med. 7:941-946.

Yamauchi T., Kamon J., Ito Y., Tsuchida A., Yokomizo T., Kita S., Sugiyama T., Miyagishi M., Hara K., Tsunoda M., Murakami K., Ohteki T., Uchida S., Takekawa S., Waki H., Tsuno N.H., Shibata Y., Terauchi Y., Froguel P., Tobe K., Koyasu S., Taira K., Kitamura T., Shimizu T., Nagai R. \& Kadowaki T. 2003. Cloning of adiponectin receptors that mediate antidiabetic metabolic effects. Nature 423:762-769.

Yaturu S., Bridges J. \& Reddy D. 2006. Decreased levels of plasma adiponectin in prediabetes, Type 2 Diabetes and coronary artery disease. Med. Sci. Monitor 12:17-20.

Yoon M.J., Lee G.Y., Chung J.J., Ahn Y.H., Hong S.H. \& Kim J.B. 2006. Adiponectin increases fatty acid oxidation in skeletal muscle cells by sequential activation of AMP-activated protein kinase, p38 mitogenactivated protein kinase, and peroxisome proliferator-activated receptor alpha. Diabetes 55:2562-2570. 